REJ - Revista de Estudios de la Justicia - No 15 - Año 2011

\title{
EL PRINCIPIO NE BIS IN IDEM EN EL DERECHO PENAL CHILENO
}

\author{
The ne bis in idem principle in Chilean criminal law
}

Juan Pablo Mañalich Raffo*

\begin{abstract}
Resumen: El artículo ofrece una reconstrucción del estatus sustantivo y procesal del principio ne bis in idem bajo el derecho penal chileno. Tras precisar su fundamento y alcance, y diferenciar sus varios contextos de pertinencia, se analizan las diversas acepciones del término "hecho" que son de significación para la operatividad del principio en cuestión, a saber: el concepto de hecho delictivo, el concepto de unidad de hecho, y el concepto de hecho (en sentido) procesal. Así se obtiene una plataforma que hace posible determinar las condiciones de aplicación y las consecuencias normativas del principio ne bis in idem en cada uno de sus tres contextos de relevancia jurídico-penal: el contexto intraprocesal, el contexto interprocesal y el concepto interjurisdiccional.
\end{abstract}

Palabras clave: ne bis in idem - pluralidad de delitos - concepto de hecho - contextos de aplicación.

\begin{abstract}
The article offers a reconstruction of the substantive and procedural status of the ne bis in idem principle under Chilean criminal law. After establishing its grounding and reach, as well as differentiating its several contexts of application, the article analyses the various meanings of the term "deed" which are significant for the principle's operation, namely: the concept of "criminal deed", the concept of "deed-unity" and the concept of the "trial's object". By this means a basis is gained in order to determine the application conditions as well as the normative consequences of the ne bis in idem principle in each one of its three contexts of relevance for the criminal law: the intra-trial context, the inter-trial context and the inter-jurisdictional context.
\end{abstract}

Keywords: ne bis in idem - offence-plurality - concept of deed - application contexts.

Asi también entiende la ley el concepto de la acción con entera regularidad: o sea, hay tantas acciones en el sentido de la ley como cuantos sean los tipos de hecho punible realizados.

(Karl Binding, Handbuch des Strafrechts.)

Por el contrario, hay que controvertir la inserción de la unidad $y$ pluralidad de delitos dentro de sus formas de aparición. Desde los días de la prueba ontológica de Dios aprendimos

\footnotetext{
* Doctor en derecho, Universidad de Bonn (2008); licenciado en ciencias jurídicas y sociales, Universidad de Chile (2004); profesor asociado del Departamento de Ciencias Penales, Facultad de Derecho, Universidad de Chile; correo electrónico: jpmanalich@,derecho.uchile.cl. Por su muy valiosa ayuda editorial, el autor agradece a Alejandra Olave Albertini y Carla Sepúlveda Penna, ayudantes ad honorem del Departamento de Ciencias Penales.
} 
que la existencia de su contenido no puede ser elemento de un concepto. Por tanto, la real existencia, simple o plural, tampoco puede ser subespecie, forma especial de aparición del delito. La pluralidad de delitos es a éste, no un supuesto de becho subordinado, sino coordinado.

(Gustav Radbruch, El concepto de acción y su importancia para el sistema del derecho penal.)

\section{El principio ne bis in idem: estructura y alcance}

\section{a) El principio ne bis in idem como prohibición de juzgamiento y de punición múltiples}

En términos generales, el principio ne bis in idem está constituido por la prohibición de que una misma persona sea juzgada y/o sancionada dos veces por un mismo hecho. En la tradición del derecho penal europeo-continental, el contenido específico del mismo se identifica con la conjunción de un estándar sustantivo de aplicación jurisdiccional de normas de sanción penal y un estándar de clausura procesal. En tanto estándar de adjudicación, el principio ne bis in idem se traduce en una prohibición de consideración o valoración múltiple de un mismo "hecho" -o más técnicamente: de una misma circunstancia o aspecto (de uno o más hechos)en la fundamentación judicial de la sanción a ser impuesta sobre una misma persona. En tanto estándar de clausura procesal, el principio se traduce en una exclusión de la posibilidad de juzgamiento de un hecho ante la existencia de otro juzgamiento (anterior o simultáneo) relativo al mismo hecho.

En algunos ordenamientos jurídicos representativos de esta tradición cultural, el principio ne bis in idem se encuentra consagrado a nivel constitucional. Éste es el caso, por ejemplo, tratándose de la Ley Fundamental alemana, cuyo art. 103, en su párrafo $3^{\circ}$, establece la prohibición de que una persona sea sancionada, con arreglo a leyes penales generales, más de una vez por un mismo hecho. Sin embargo, la doctrina dominante asume que esa disposición constitucional sólo configura un impedimento para el juzgamiento múltiple por un mismo hecho, entendiéndose por "hecho", en este contexto específico, todo el "suceso vital" al cual puede encontrarse referido el juzgamiento en cuestión. Se discute, ahora bien, si este "concepto jurídico-procesal de hecho", ha de entenderse de un modo exclusivamente fáctico, o bien si, por el contrario, ha de entenderse modelado por criterios normativos. Pero es bastante pacífica la tesis de que este concepto jurídico-procesal de hecho es en todo caso independiente, en cuanto a sus presupuestos y su alcance, del concepto jurídico-penal de hecho en sentido sustantivo. ${ }^{1}$

\footnotetext{
${ }^{1}$ Kindhäuser, Urs: Strafprozessrecht, 2006, \ 25/12.
} 
La consecuencia fundamental de ello es que una pluralidad de hechos delictivos en el sentido del derecho penal sustantivo puede llegar a constituir, bajo determinadas condiciones, un solo hecho en sentido procesal, cuyo juzgamiento queda entonces proscrito en caso de haber existido un ejercicio de jurisdicción a su respecto previamente. ${ }^{2} \mathrm{Y}$ de acuerdo con la comprensión dominante al respecto en la doctrina alemana, esta función de clausura procesal del principio ne bis in idem, constitucionalmente consagrado, se corresponde íntegramente con el efecto de cosa juzgada material de la respectiva sentencia firme, cuya extensión queda determinada, entonces, por la extensión del correspondiente hecho en sentido procesal. ${ }^{3}$ Y la misma variable fija, por lo demás, el alcance del efecto de litis pendencia asociado a un eventual conocimiento judicial todavía en curso de ese mismo hecho. ${ }^{4}$

Tratándose de ordenamientos cuyos textos constitucionales no contienen cláusulas semejantes -como es el caso del derecho español y del derecho chileno, entre otros-, y más allá de que pueda identificarse un fundamento constitucional indirecto para el principio en cuestión, ${ }^{5}$ es de todas formas posible invocar disposiciones de tratados internacionales, ratificados por los respectivos Estados, para conferirle así un estatus supralegal. En lo inmediatamente relevante para el derecho chileno, los tratados vinculantes son, a este respecto, el Pacto Internacional de Derechos Civiles y Políticos y la Convención Americana sobre Derechos Humanos. Pero aquí es necesario observar que ambos tratados consagran el principio ne bis in idem exclusivamente en su dimensión de estándar procesal. Esto impone la carga de dar cuenta de algunas peculiaridades de su consagración en uno y otro texto.

El art. $14 \mathrm{~N}^{\circ} 7$ del Pacto Internacional de Derechos Civiles y Políticos dispone que "[n]adie podrá ser juzgado ni sancionado por un delito por el cual haya sido condenado o absuelto por una sentencia firme [...]". Si bien la disposición recurre tanto a la noción de juzgamiento como a la de sanción para articular la garantía, lo cual podría sugerir que ésta resulta comprensiva tanto de la dimensión procesal como de la dimensión sustantiva del principio, ello resulta de inmediato contrarrestado por la cláusula que hace explícito el presupuesto de la existencia de una sentencia condenatoria o absolutoria firme. En tal medida, la garantía no incorpora la prohibición de que en único ejercicio de jurisdicción se

\footnotetext{
2 Kindhäuser, Urs: Lehr- und Praxiskommentar zum Strafgesetz̧uch [LPK-StGB], 2010, ante $\iint 52-55$, n.m. 6.

${ }^{3}$ Kindhäuser, Urs: Strafprozessrecht (nota 1), \25/34.

${ }^{4}$ Ibid, $\$ 25 / 6$.

5 Así lo ha afirmado, en relación con el derecho chileno, la Corte Suprema chilena, por sentencia de 24 de marzo de 2009, rol No 169 , en referencia a un caso de imposición de multas en materia laboral, en cuyo considerando $7^{\circ}$ se sostiene que el principio ne bis in idem "configura una garantía individual innominada, originaria del Derecho Natural y cuyo sustento se halla en el debido proceso legal exigido por el $\mathrm{N}^{\mathrm{o}} 3$ del artículo 19 de la Constitución Política nacional y en la idea de que al admitirse una segunda condena por la misma infracción se produce una manifiesta desproporción entre la falta y su castigo".
} 
tome en consideración dos veces una misma circunstancia para fundamentar o agravar la sanción de cuya imposición se trata.

El art. $8^{\circ} \mathrm{N}^{\mathrm{o}} 4$ de la Convención Americana sobre Derechos Humanos, por su parte, consagra el principio, en su sola dimensión procesal, en términos todavía más restrictivos, al disponer que "[e]l inculpado absuelto por una sentencia firme no podrá ser sometido a nuevo juicio por los mismos hechos". Aquí es fundamental reparar en la restricción del alcance de la garantía únicamente a aquellos casos en que el juzgamiento previo ha concluido en el pronunciamiento de una decisión de absolución, lo cual significa que la garantía no encuentra siquiera aplicación tratándose de casos en que ha existido una sentencia condenatoria previa respecto de "los mismos hechos". Esto ciertamente no admite interpretarse en el sentido de que la convención autorizaría, entonces, la imposición de una nueva sanción por hechos que ya hubieran dado lugar a la imposición de una sanción impuesta por una sentencia condenatoria previa. Más bien, cabe entender que la Convención pretende fundar la inadmisibilidad jurídica de esta última posibilidad, directamente, en el principio de legalidad de la pena, establecido en su art. $9^{\circ}$, específicamente bajo la prohibición de que se imponga una "pena más grave que la aplicable en el momento de la comisión del delito".

La consideración anterior, sin embargo, no basta para dar cuenta del cabal alcance que doctrinalmente se atribuye al principio ne bis in idem en sentido sustantivo. Pues la prohibición de sanción múltiple por un mismo hecho no se encuentra restringida al caso hipotético de que un tribunal pudiera imponer dos veces la pena legalmente prevista para el autor de un hecho delictivo determinado, lo cual, como instancia de incorrecta aplicación del derecho, constituiría ya un error aritmético (y en tal medida, un error lógico). ${ }^{6}$ El núcleo de significación práctica del principio como estándar sustantivo concierne, más bien, aquellas situaciones en que el hecho objeto del juzgamiento puede satisfacer dos o más descripciones de formas de comportamiento delictivo, en términos de lo que se conoce como un concurso de delitos. Y ante tales situaciones, el principio ne bis in idem se vuelve específicamente operativo al modo de una "prohibición de doble valoración" (Doppelverwertungsverbot), de manera tal que, en la medida en que una misma circunstancia o aspecto del hecho (o de los hechos) objeto de juzgamiento tenga relevancia bajo más de una descripción, haya que reconocer el carácter "aparente" o impropio del respectivo concurso de delitos, para evitar así una contravención de la prohibición de punición múltiple por un mismo hecho.

En esta dimensión como estándar sustantivo de adjudicación, orientado a la evitación de fundamentar o agravar una sanción por un mismo hecho, el principio ne bis in idem no representa más que una concreción de la prohibición de exceso que se deriva del principio (general) de proporcionalidad: considerar dos veces un mismo hecho -o más exactamente, la misma propiedad de un hecho-

\footnotetext{
${ }^{6}$ Puppe, Ingeborg: Strafrecht Allgemeiner Teil, tomo II, 2005, \52/2.

${ }^{7}$ Ibid.
} 
para fundamentar o agravar la sanción a ser impuesta sobre una persona, constituye una contravención de esa prohibición de exceso. Lo fundamental es que, desde este punto de vista, el principio ne bis in idem representa un estándar vinculante para el adjudicador, pero no sin más, al menos directamente, para el legislador. Esto, porque la premisa metodológica que subyace a la aplicación del principio, en su modalidad de prohibición de doble valoración, consiste en la necesidad de evitar las consecuencias de una eventual redundancia legislativa circunstancial, asociada a la superposición de los supuestos de hecho de dos o más normas de sanción en relación con un mismo objeto de subsunción. Esto es precisamente lo que se constata cada vez que se afirma un concurso impropio o aparente de delitos, que da lugar a la exclusión de la aplicación de las consecuencias que normalmente estarían asociadas a un auténtico concurso (real o ideal) de delitos.

Es crucial reparar aquí en que la prohibición no se ve quebrantada, por lo mismo, si el reconocimiento de un auténtico concurso de delitos expresa adecuadamente, y de conformidad con la representación legislativa, la magnitud de desvalor correspondiente al hecho o a los hechos imputables a una determinada persona. Ello se manifiesta en la proposición doctrinaria según la cual la prohibición de doble valoración, en la cual se traduce el principio ne bis in idem, tendría como contrapunto preciso lo que (en los términos de la doctrina penal alemana) se conoce como un "mandato de exhaustividad" (Ausschöpfungsgebot): la sentencia condenatoria ha de hacer explícito todo el contenido de ilicitud de las descripciones de comportamiento delictivo cuya realización es (simultáneamente) imputable a una misma persona. ${ }^{8}$

Por ello, si hay base suficiente para atribuir al legislador la sobrevaloración de una misma propiedad de determinado hecho, entonces esa sobrevaloración no es prima facie interpretable como redundancia, sino como énfasis en su valoración negativa. Ello es así hasta el punto de que cada tipificación de un delito compuesto, esto es, un delito que se estructura como la conjunción de dos (o más) delitos distintos, no es más que la articulación de un reconocimiento legislativo específico del correspondiente concurso (ideal o medial).

\section{b) E1 principio ne bis in idem como estándar de derecho internacional penal}

El alcance del principio ne bis in idem, desdoblado en sus funciones de prohibición de punición múltiple y de juzgamiento (o persecución) múltiple por un mismo hecho, se encuentra en todo caso circunscrito al ámbito correspondiente al ejercicio de jurisdicción estatal. Incluso bajo su consagración en tratados

\footnotetext{
${ }^{8}$ Ibid, $\int 52 / 3$.

9 Así, por ejemplo, la tipificación del robo (con violencia o intimidación en las personas) no es sino la tipificación de una combinación medial de una coacción (mediante violencia o mediante amenaza) y un hurto.
} 
internacionales orientados a la protección de derechos fundamentales, el principio ne bis in idem "afecta a una sola unidad jurisdiccional"; ${ }^{10}$ o de acuerdo con una formulación todavía más categórica: "La prohibición de punición múltiple del derecho internacional sólo prohíbe la condena por un mismo hecho al interior de cada Estado"."11

Esto descansa, como es obvio, en el reconocimiento de la soberanía de cada Estado, una de cuyas dimensiones específicas está constituida, precisamente, por la autonomía del ejercicio de su propia jurisdicción, así como de su propia potestad punitiva. Lo cual puede conllevar dificultades desde el punto de vista de eventuales conflictos de jurisdicción, en la medida en que, como desarrollo del derecho internacional, se amplíen las bases de ejercicio de jurisdicción extraterritorial susceptibles de ser invocadas por cada Estado. ${ }^{12}$ Ciertamente, ello no significa que un Estado, en ejercicio de su soberanía, no pueda adoptar un principio de reconocimiento del ejercicio de jurisdicción de otros Estados para así condicionar negativamente el ejercicio de su propia jurisdicción. ${ }^{13}$ Pero sí significa que, a menos que un Estado efectivamente se someta a ese constreñimiento, el ejercicio de su propia jurisdicción, así como de sus propias potestades sancionatorias, no queda en modo alguno sometido por el eventual ejercicio de jurisdicción de otro Estado, aun cuando uno y otro puedan referirse a un mismo hecho.

A este respecto, resulta ilustrativo el proceso tendiente al progresivo afianzamiento de un principio de "reconocimiento mutuo" entre los Estados miembros de la Unión Europea, proceso marcado por la consagración (matizada) del principio ne bis in idem en el marco del Acuerdo Shengen. ${ }^{14}$ En efecto, el art. 54 del Convenio de Implementación del Acuerdo Shengen dispone que

$[u]$ na persona que haya sido juzgada en sentencia firme por una Parte contratante no podrá ser perseguida por los mismos hechos por otra Parte contratante, siempre que, en caso de condena, se haya ejecutado la sanción, se esté ejecutando o no pueda ejecutarse ya según la legislación de la Parte contratante donde haya tenido lugar la condena.

\footnotetext{
10 Colomer Hernández, Ignacio: "Conflictos de jurisdicción, non bis in idem y litispendencia internacional en la Unión Europea”, en Arroyo Zapatero y Nieto Martín (coords.), El principio de ne bis in idem en el Derecho penal europeo e internacional, 2007, p. 69; Satzger, Helmut y Kayser, Julia: "Ne bis in idem en el derecho penal internacional: muchas preguntas a segunda vista", en Arroyo Zapatero y Nieto Martín (coords.), El principio de ne bis in idem en el Derecho penal europeo e internacional, 2007, p. 97.

${ }^{11}$ Hecker, Bernd: Europäisches Strafrecht, 2010, \13/2.

12 Ibid, $513 / 5$ s.

13 Aquí destacan, paradigmáticamente, los casos de Holanda y Canadá. Al respecto Satzger, Helmut y Kayser, Julia: "Ne bis in idem en el derecho penal internacional..." (nota 10), p. 97.

${ }^{14}$ La Carta de Derechos Fundamentales de la Unión Europea también contempla, en su art. 50, una consagración del principio ne bis in idem con alcance transnacional. Al respecto Hecker, Bernd: Europäisches Strafrecht (nota 11), \$13/12 ss.
} 
En la aplicación de esta cláusula, y a pesar de la existencia de importantes desacuerdos interpretativos entre las autoridades doctrinarias, ${ }^{15}$ la jurisprudencia del Tribunal de Justicia de la Comunidad Europea muestra una importante orientación hacia una progresiva ampliación del ámbito de aplicabilidad del principio tratándose de eventuales conflictos de jurisdicción entre "EstadosShengen". Esto, en atención tanto al factor de lo que cabe entender como "sentencia firme" como al factor de lo que cabe entender como "los mismos hechos". ${ }^{16}$

Respecto de lo segundo, es especialmente importante que, con ocasión de su decisión recaída en el "Asunto Van Esbroeck", el Tribunal se haya inclinado decididamente hacia una interpretación de la expresión "los mismos hechos" en clave puramente fáctica, esto es, con total prescindencia de su eventual calificación jurídica desde el punto de vista de los ordenamientos de los Estados de cuya jurisdicción eventualmente concurrente se trate. ${ }^{17}$ Ello se ha visto posteriormente complementado por lo afirmado por el Tribunal, en aplicación del mismo art. 54, al fallar el "Asunto Van Straaten", en el sentido de que la "identidad de hecho", para los efectos de la aplicación de la garantía del ne bis in idem, puede ser relativa. ${ }^{18}$

Sin embargo, un dato fundamental acerca de este desarrollo crecientemente expansivo se refiere a las consideraciones materiales que la propia jurisprudencia del Tribunal de Justicia de la Comunidad Europea ha tendido a esgrimir para sustentar dicho desarrollo: preponderantemente, el principio de la confianza mutua entre los Estados, pero también el favorecimiento de la libre circulación de personas entre los territorios de los "Estados-Shengen". ${ }^{19}$ Tal régimen de reconocimiento jurisdiccional recíproco descansa, por ello, sobre un trasfondo de condiciones de integración política que justifican el condicionamiento del ejercicio de las potestades soberanas de cada Estado en atención al ejercicio de esas mismas potestades por parte de los demás Estados así vinculados. ${ }^{20}$ En cambio, tratándose de escenarios en que no se dan semejantes condiciones de integración política autónomamente coordinada por los Estados, no parece imaginable la activación de un régimen de reconocimiento internacional del principio ne bis in idem.

\footnotetext{
${ }^{15}$ Kindhäuser, Urs: Strafprozessrecht (nota 1), \ 35/29.

16 Sarmiento, Daniel: "El principio ne bis in idem en la jurisprudencia del TJCE”, en Arroyo Zapatero y Nieto Martín (coords.), El principio de ne bis in idem en el Derecho penal europeo e internacional, 2007, pp. 41 ss. Para un análisis pormenorizado véase, entre otros, Hecker, Bernd: Europäisches Strafrecht (nota 11), \13/23 ss., 53 ss.

17 Sarmiento, Daniel: "El principio ne bis in idem..." (nota 16), pp. 45 ss.

${ }^{18}$ Ibid, p. 49.

${ }^{19}$ Sarmiento, Daniel: "El principio ne bis in idem..." (nota 16), pp. 43 ss.

${ }^{20}$ Así Hecker, Bernd: Europäisches Strafrecht (nota 11), \13/35.
} 


\section{c) Los contextos del principio ne bis in idem}

La lección fundamental que arroja la revisión precedente de algunos antecedentes acerca del estatus y alcance del principio ne bis in idem concierne a lo imprescindible de diferenciar los contextos particulares en que puede activarse su aplicación. Pues en el marco de cada uno de estos contextos pueden plantearse preguntas específicas acerca de la concreción del principio o bien como estándar de clausura procesal o bien como estándar sustantivo de adjudicación.

El primer contexto que necesita ser perfilado diferenciadamente es lo que cabría llamar el "contexto interjurisdiccional". Es aquí donde el principio ne bis in idem, en términos del derecho comparado, opera con el menor grado de conclusividad. Y la razón para ello se encuentra en que dicho principio se halla históricamente construido sobre la base de una hipótesis de unicidad de jurisdicción, en el sentido de que tanto la restricción de las oportunidades procesales para el juzgamiento como la restricción de la acumulación de sanciones a ser impuestas en relación con un mismo hecho -más allá de cómo se entienda esto último- son dependientes del punto de vista de un mismo sistema jurisdiccional soberano. Esto es lo que enseña el examen de las propuestas de internacionalización del principio ne bis in idem: en este nivel, el principio en cuestión sólo puede obtener validez sobre la base de la adopción de políticas de reconocimiento mutuo y medidas de cooperación internacional que efectivamente limiten las posibilidades de ejercicio de las potestades jurisdiccionales y sancionatorias de los Estados involucrados.

En un caso propio del contexto interjurisdiccional, en que ha de determinarse si el tribunal de un Estado -dando por sentada su competenciapuede juzgar o imponer una sanción por uno o más hechos delictivos que ya han sido objeto de juzgamiento o fundamento de la imposición de una sanción por parte de un órgano jurisdiccional extranjero, la cuestión se reduce a si el derecho aplicable para aquel tribunal contempla o no un reconocimiento del ejercicio de jurisdicción o de la potestad sancionadora por parte de éste. Ciertamente, la respuesta a esta pregunta es siempre contingente. Bajo el derecho chileno, como habrá de verse todavía, la respuesta está dada, en lo relativo tanto a la prohibición del juzgamiento múltiple como a la prohibición de sanción múltiple, por las reglas del art. 13 del Código Procesal Penal.

El contexto contrapuesto se identifica con lo que cabría llamar, correspondientemente, el "contexto intrajurisdiccional". Según ya se anticipara, este contexto, definido por la circunstancia de la posible multiplicidad de instancias de juzgamiento o punición al interior de un mismo sistema jurisdiccional, representa el ámbito de aplicación históricamente autoevidente para el principio ne bis in idem. De ahí que la consagración de éste en tratados internacionales sea hegemónicamente entendida como exclusivamente vinculante para el ejercicio de jurisdicción por parte de cada Estado considerado en sí mismo, sin atender, en cambio, a posibles situaciones de concurrencia de jurisdicción 
REJ - Revista de Estudios de la Justicia - No 15 - Año 2011

entre Estados. Pero aquí es necesario introducir una distinción ulterior entre dos subcontextos, que cabría denominar el "contexto interprocesal" y el "contexto intraprocesal".

La razón para esto está en que sólo en un contexto interprocesal -esto es, en un contexto en que dos o más procesos pudieran llevarse a efecto (sucesiva o simultáneamente) en relación con un mismo conjunto de circunstancias de hecho- puede venir en consideración, en tanto estándar de clausura procesal, una prohibición de juzgamiento múltiple. Y en la medida en que en este contexto interprocesal, por definición, un impedimento del juzgamiento múltiple por un mismo conjunto de hechos ha de operar con anterioridad al eventual impedimento de la imposición de sanciones múltiples por ese mismo complejo de hechos, aquí puede resultar superfluo reconocer, independientemente, la prohibición de punición múltiple, en tanto estándar sustantivo de adjudicación. Pues estando proscrito el juzgamiento múltiple, por definición no podrá llegarse a un escenario de eventual punición múltiple, en tanto el estándar de clausura procesal sea observado. Esto explica, como se mostrará más adelante, el tenor de la consagración del efecto de cosa juzgada (material), en el sentido de un principio de "única persecución", en el art. $1^{\circ}$ del Código Procesal Penal chileno, que vuelve eficaz la prohibición de dos o más juzgamientos sucesivos; su correlato, que hace efectiva la prohibición de dos o más juzgamientos simultáneos, está constituido por la excepción de litis pendencia.

Finalmente, como segundo subcontexto del contexto intrajurisdiccional, cabe diferenciar lo que puede denominarse el "contexto intraprocesal". Aquí se trata de situaciones en que la prohibición de punición múltiple se hace operativa como estándar de adjudicación en exclusiva atención a los hechos delictivos que son objeto de un mismo juzgamiento. En tal medida, este contexto está definido por la imposibilidad de que el principio ne bis in idem resulte aplicable como prohibición de juzgamiento múltiple. Una lección de derecho comparado consiste, a este respecto, en el hallazgo de que, al interior de un mismo ordenamiento jurídico, el alcance exhibido por la prohibición de punición múltiple en este contexto intraprocesal puede ser congruente o incongruente. En el derecho estadounidense, la "cláusula de la doble exposición" tiende a ser tenida por aplicable en iguales términos en uno y otro contexto. ${ }^{20 \mathrm{~b}}$ En la tradición del derecho europeo-continental, en cambio, la prohibición de la punición múltiple en el contexto intraprocesal se hace operativa a través de las reglas sobre unidad de acción y concursos de delitos, sin coincidir en su extensión con el conjunto de garantías procesales asociadas a la cosa juzgada y la litis pendencia. Según se mostrará más adelante, ésta es también la solución reconocible en el derecho penal chileno.

20b En detalle al respecto Mañalich, Juan Pablo: "El concurso de delitos: bases para su reconstrucción en el derecho penal de Puerto Rico", Revista Jurídica de la Universidad de Puerto Rico 74 (2005), pp. 1021 ss., 1053 ss., con ulteriores referencias. 


\section{El concepto de hecho}

\section{a) La primacía del derecho penal frente al derecho procesal penal}

La determinación del alcance preciso del conjunto de prohibiciones que se identifican con el principio ne bis in idem pasa, en lo fundamental, por la determinación de su respectivo objeto. $\mathrm{Y}$ aquí es necesario reparar en la ambigüedad que exhibe el término "un mismo hecho" cuando se habla, para caracterizar al principio, de la prohibición de juzgar y sancionar a una persona dos (o más) veces por "el mismo hecho". ${ }^{21}$ Pues lo que cabe entender por "el mismo hecho" en el sentido (genérico) del principio ne bis in idem puede variar sobremanera, según cómo se encuentre jurídicamente reconocida la respectiva prohibición (de juzgamiento o de punición múltiple) en el contexto de que se trate. Por ello, es imprescindible diferenciar sistemáticamente los múltiples sentidos que pueden ser atribuidos a esa expresión genérica, para después examinar cuáles son los términos bajo los cuales el derecho chileno, en cada contexto, articula las distintas modalidades de proscripción del bis in idem.

El punto de partida a este respecto está constituido por la ya tradicional contraposición de un concepto de hecho propio del derecho penal sustantivo (en lo que sigue: "concepto jurídico-penal de hecho") y un concepto de hecho propio del derecho procesal penal (en lo que sigue: "concepto procesal de hecho"). En lo esencial, lo que aquí aparece es la constatación de que el concepto jurídico-penal de hecho no tiene por qué coincidir necesariamente con el concepto de hecho que hacen suyas las reglas que instituyen y regulan el proceso penal. Y esto se sigue de la adopción de un punto de vista funcional: en la medida en que las funciones desempeñadas por el derecho penal (sustantivo) y el derecho procesal penal no sean idénticas, es enteramente posible que, en tanto categoría de uno y otro ámbito jurídico, el concepto de hecho exhiba un contenido diferente, según corresponda.

Lo anterior no deja de ser trivial. Lo importante es combinar esta consideración trivial con la consideración menos trivial de que las funciones desempeñadas por el derecho procesal penal sólo pueden ser entendidas como funciones secundarias, por referencia a su contribución a la realización de las funciones (primarias) atribuibles al derecho penal. Lo cual descansa en la idea de que el derecho penal se realiza a través del derecho procesal penal. ${ }^{22} \mathrm{Y}$ si bien esta proposición sigue representando un lugar común, de ella puede extraerse una base para establecer una relación de prioridad entre la definición del concepto jurídicopenal y la definición del concepto procesal de hecho.

\footnotetext{
21 Piña, Juan Ignacio: Derecho Penal. Fundamentos de la responsabilidad, 2010, p. 256.

${ }^{22}$ Fundamental Binding, Karl: Handbuch des Strafrechts, 1991, pp. 192 ss.; véase también, en clave sociológica, Piña, Juan Ignacio: Derecho Penal (nota 21), pp. 99 ss.
} 
Sin que sea pertinente aquí detenerse pormenorizadamente en ello, y asumiendo la perspectiva de una teoría expresiva o comunicativa de la pena, ${ }^{23}$ puede sostenerse que la función del derecho penal se identifica con el restablecimiento simbólico de la vigencia de normas fundamentales para la coexistencia social, legitimadas en atención al principio de protección de bienes jurídicos, a través de la institucionalización de la irrogación de un mal de cierta naturaleza como una respuesta jurídica que expresa desaprobación por el quebrantamiento imputable de una (o varias) de esas normas. ${ }^{24}$ Así, el conflicto que determina el horizonte de operación del derecho penal se corresponde con el conflicto que representa el quebrantamiento imputable de una norma semejante frente a la pretensión (estatal) de vigencia generalizada de esa misma norma.

Pero la confianza generalizada en la vigencia de una norma tal puede verse afectada ya por la sospecha de que ella haya sido quebrantada. De esto resulta, entonces, que el horizonte de operación del derecho procesal penal está constituido por la sospecha, y por ende, por la incertidumbre acerca de que haya tenido o no lugar tal quebrantamiento imputable de una norma, ${ }^{25}$ esto es, la perpetración de un delito. De este modo, el proceso persigue la superación de esa incertidumbre, sea por la vía de refutar la sospecha, sea por la vía de confirmarla; y sólo en este último resulta procedente, a través del pronunciamiento de la correspondiente sentencia condenatoria, la imposición de la sanción penal correspondiente.

La manera en que la operación del derecho procesal contribuye a la realización de la función del derecho penal, bajo ese horizonte de sospecha, admite ser desglosada en una tripartición de funciones: una función de verdad, una función de justicia formal y una función de certeza jurídica. ${ }^{26} \mathrm{La}$ función de verdad concierne el problema del establecimiento, como "cuestión histórica", de la existencia del quebrantamiento imputable de la norma que pretende ser procesalmente achacado a una persona; la función de justicia formal, por su parte, afecta el problema de la definición de la forma del procedimiento a través del cual pueda obtenerse la resolución imparcial de la sospecha de la perpetración de un delito; y la función de certeza jurídica, finalmente, se conecta con la necesidad de que el conflicto procesal, constituido por la incertidumbre acerca de la efectividad de la perpetración del (eventual) delito, sea resuelto en forma definitiva.

Puesto que estas funciones pueden encontrarse en relación de tensión recíproca, la estructura del proceso penal refleja una serie de mecanismos de resguardo, que expresan "soluciones de compromiso". Para dar un ejemplo: en el carácter excepcionalísimo de la impugnación de una sentencia firme, que como tal

$23 \mathrm{Al}$ respecto Mañalich, Juan Pablo: "La pena como retribución”, Estudios Públicos 108, 2007, pp. 135 ss., 161 ss., con ulteriores referencias.

${ }^{24}$ En detalle Mañalich, Juan Pablo: Terror, pena y amnistía. El derecho penal ante el terrorismo de Estado, 2010 , pp. 53 ss., 89 ss.

${ }^{25}$ Kindhäuser, Urs: Strafprozessrecht (nota 1), $\int 1 / 5$ ss.

${ }^{26} \mathrm{Ibid}, \int 1 / 8 \mathrm{ss}$. 
ya reclama fuerza de cosa juzgada, a través de un recurso de revisión, se expresa la solución de un potencial conflicto entre la función de verdad y la función de certeza jurídica que ha de desempeñar el proceso.

En lo que aquí interesa, lo anterior se traduce, también bajo el derecho chileno, en que el concepto procesal de hecho, por oposición al concepto jurídicopenal de hecho, exhiba mayor alcance, en razón de ser menos exigentes las condiciones para el reconocimiento de un único hecho en sentido procesal. Como se mostrará más abajo, esto se explica porque en la articulación del concepto procesal de hecho, precisamente, se hacen patentes tanto la función de justicia formal -incluidas aquí determinadas consideraciones de economía procesalcomo la función de certeza jurídica. Antes, empero, es necesario partir examinando la noción primaria, que es, según ya se afirmara, la representada por el concepto jurídico-penal de hecho.

\section{b) El concepto jurídico-penal de hecho delictivo}

En términos del derecho penal sustantivo, el sentido primario en que puede hablarse de "hecho" es para designar, propiamente, un determinado hecho delictivo, esto es, un hecho que se distingue por constituir un delito. Para los efectos del principio ne bis in idem, lo que importa es dar cuenta de cómo se individua un delito, de modo tal de poder identificar bajo qué condiciones existe un único delito. El criterio para ello es evidente sin más: un delito está constituido por una realización imputable de un tipo delictivo, esto es, de una determinada descripción de una forma de comportamiento delictivo. Es fundamental advertir, sin embargo, que aquí aparecen envueltas dos cuestiones de identidad, que pueden y deben ser diferenciadas: (a) una cuestión de identidad relativa al tipo delictivo realizado, por un lado, y (b) una cuestión de identidad relativa a la concreta instancia de realización de ese tipo delictivo, por otro. ${ }^{27}$

Para la existencia de un solo delito es necesario, por una parte, que venga en consideración la realización (imputable) de un solo tipo delictivo; si en un caso cualquiera, en cambio, se constata la realización de más de un tipo delictivo, habrá que reconocer tantos delitos como sean los tipos delictivos realizados, con total independencia de si la realización de los distintos tipos delictivos tiene lugar a través de una sola acción (u omisión), o bien a través de varias acciones ( $\mathrm{u}$ omisiones). Lo que se da en una situación semejante, entonces, es un concurso (ideal o real) de delitos entre cada una de las realizaciones de los diferentes tipos delictivos. Pues en este sentido, hay tantos hechos delictivos como tipos delictivos realizados (de manera imputable) ${ }^{28} \mathrm{Y}$ la única restricción que impone aquí el principio ne bis in idem, en la forma de la prohibición de doble valoración, afecta

\footnotetext{
${ }^{27}$ Fundamental al respecto Moore, Michael: Act and Crime. The Philosophy of Action and its Implications for Criminal Law, 1993, pp. 314 ss., 325 ss., 365 ss., 383 ss.

${ }^{28}$ Binding, Karl: Handbuch (nota 22), pp. 565 ss. En igual sentido Jakobs, Strafrecht Allgemeiner Teil, pp. $32 / 12$ ss.
} 
aquellos casos en que, por razones formales o materiales, dos o más de los tipos delictivos realizados puedan ser considerados (parcialmente) idénticos entre sí. Pues en tal situación, por exigencia del principio ne bis in idem, habrá que reconocer el carácter "aparente" del concurso de delitos en cuestión, de conformidad con alguno de los criterios -legalidad, subsidiariedad, consunción, etc.- que hacen posible su fundamentación.

Pero para la existencia de un solo delito también es necesario, por otra parte, que el tipo delictivo de cuya realización se trata haya sido realizado una sola vez. Pues es obvio que si una misma descripción de comportamiento delictivo se ve realizada más de una vez, prima facie habrá que reconocer tantos delitos como instancias de realización del tipo delictivo en cuestión. Y la única restricción que puede hacerse operativa aquí está asociada a la posibilidad de que lo que en principio pudiera parecer como un conjunto de varias realizaciones de un mismo tipo delictivo, también por exigencia del principio ne bis in idem, en definitiva tenga que ser entendido, por razones formales o materiales, como una sola realización del tipo delictivo en cuestión. Esto es precisamente lo que se da en los casos en que se reconoce una unidad de acción (u omisión) delictiva, cuya consecuencia es la negación de un concurso de delitos y la constatación, en cambio, de un solo delito, esto es, de un solo hecho delictivo.

Lo crucial de este análisis del concepto de hecho delictivo, en lo que es relevante para los problemas de individuación que interesan bajo el principio ne bis in idem, está en la idea de que el primer paso siempre está constituido por la pregunta de si en un caso cualquiera concurren una o varias realizaciones de uno o más tipos delictivos, y no así por la pregunta de cuántas acciones (u omisiones) concurren. Esta última pregunta sólo tiene relevancia una vez que se ha establecido que concurren varias realizaciones de uno o más tipos delictivos. Esto quiere decir, en otros términos, que el concepto de hecho delictivo del derecho penal sustantivo es un concepto intensional (= no extensional), ${ }^{29}$ en el sentido de que la identificación de un determinado hecho delictivo es siempre relativa a, o dependiente de, una determinada descripción: cada realización (imputable) de un determinado tipo delictivo cuenta como un hecho delictivo per se.

Así, si a través de un solo disparo de un arma de fuego tiene lugar la realización de dos tipos delictivos diferentes, por ejemplo, la descripción del homicidio y la descripción del aborto -porque el disparo impacta a una mujer embarazada, produciendo la muerte de ésta y también la del feto anidado en su útero-, entonces hay dos hechos delictivos diferentes, en relación de concurso heterogéneo (= realización de múltiples tipos delictivos). Y asimismo, si a través de la detonación de una bomba tiene lugar dos veces la realización de un mismo tipo delictivo, por ejemplo, la descripción del homicidio -porque a consecuencia de la explosión resultan muertas dos personas-, entonces también hay dos hechos

29 Acerca de disputa entre tesis extensionalistas e intensionalistas a propósito del problema de la identificación y cuantificación de acciones, véase Moore, Michael: Act and Crime (nota 27), pp. 280 ss. 
delictivos diferentes, en relación de concurso homogéneo $(=$ múltiples realizaciones de un tipo delictivo). En uno y otro caso, es correcto que la condena exprese el reproche correspondiente a cada uno de los delitos cometidos, sin que venga en consideración, por lo mismo, un bis in idem.

\section{c) El concepto jurídico-penal de unidad de hecho}

Pero el derecho penal sustantivo también conoce una noción diferente de "hecho", a saber, aquella que sirve para la calificación de un (auténtico) concurso de delitos como un concurso ideal, precisamente en atención a que las dos o más realizaciones del mismo o de varios tipos delictivos tienen lugar en "unidad de hecho". Así, en el primero de los ejemplos mencionados precedentemente puede decirse que el delito homicidio y el delito de aborto han sido cometidos a través de "un solo hecho" - consistente en un único disparo de un arma de fuego, por el cual se causara tanto la muerte de la mujer embarazada como la muerte del feto-, tal como lo prevé el art. 75 del Código Penal.

Aquí es crucial, en todo caso, advertir que este concepto de (unidad de) hecho, en virtud de cuya aplicación la concurrencia de dos o más hechos delictivos (imputables a la misma persona) asume la forma de un concurso ideal, no es el mismo concepto de hecho que se tiene en cuenta para afirmar que, en ese mismo caso, el homicidio y el aborto constituyen (dos) hechos delictivos diferentes. ${ }^{30}$ Cuando se dice, en atención al caso ya mencionado, que el tipo delictivo del homicidio y el tipo delictivo del aborto son realizados en unidad de hecho, este concepto de hecho funciona como un concepto débilmente extensional (= no-intensional), esto es, como un concepto que hace posible la identificación de un solo hecho no por referencia exclusiva a alguna de las dos descripciones en cuestión, sino más bien a través de esas mismas descripciones. ${ }^{31}$

Ello, porque la unificación como un solo hecho (en sentido débilmente extensional) de las dos o más realizaciones del mismo o de distintos tipos delictivos por definición no puede fundarse en una identificación de éstas como una sola realización típica, puesto que el presupuesto de reconocimiento de un concurso ideal lo representa, precisamente, una pluralidad de hechos delictivos concurrentes, tal como lo sugiere, por lo demás, la correlación de los encabezados de los arts. 74 y 75 del Código Penal. Y tampoco parece demasiado sensato recurrir a un criterio "naturalista", en el sentido, por ejemplo, de que habría unidad de acción siempre que las realizaciones típicas concurrentes hayan tenido lugar a través de un mismo movimiento corporal voluntario, criterio que ni

\footnotetext{
${ }^{30}$ Binding, Karl: Handbuch (nota 22), pp. 573 ss., en relación con el doble significado del concepto de acción (Handlung) bajo el Código Penal (imperial) alemán de 1871.

${ }^{31}$ La caracterización de este concepto de unidad de hecho como débilmente extensional se explica porque aquí sigue siendo determinante la cuestión de cómo sea descrito el hecho en cuestión; el punto es que se reconoce como un solo hecho un objeto de subsunción que satisface dos o más descripciones alternativas.
} 
siquiera alcanza a ser aplicable respecto de cualquier forma de comportamiento delictivo; piénsese, por ejemplo, en un delito de omisión.

Antes bien, lo correcto es recurrir a un criterio con relevancia normativa para fundamentar la unificación (relativa) de las diferentes realizaciones típicas concurrentes, que en todo caso explique el tratamiento punitivo más favorable que el legislador asocia al concurso ideal frente al concurso real, que es aquella forma de concurso (auténtico) que se distingue, precisamente, por no presuponer una unidad de hecho entre las distintas realizaciones típicas concurrentes. ${ }^{32} \mathrm{Y}$ tal criterio tendría que descansar en la posibilidad de una aproximación de las distintas realizaciones típicas imputables a la misma persona, en el sentido de una relación de identidad total o parcial entre las respectivas acciones ejecutivas, ${ }^{33}$ bajo un test de "evitabilidad conjunta": si para el autor de los varios hechos delictivos concurrentes hubiera sido posible evitar las dos o más realizaciones típicas a través de la omisión de una misma acción, entonces puede afirmarse una unidad de hecho. ${ }^{34}$ En el ejemplo ya recurrentemente mencionado: puesto que para el autor del homicidio y del aborto era posible evitar ambas realizaciones típicas absteniéndose de efectuar el disparo del arma de fuego, puede concluirse que ambos hechos delictivos (en sentido intensional) han sido cometidos en unidad de hecho (en sentido extensional), esto es, en una relación de concurso ideal.

Es importante advertir, sin embargo, que este criterio de reconocimiento de una unidad de hecho, conducente a hacer aplicable el régimen punitivo correspondiente al concurso ideal, sólo pretende proveer una base racional que explique, aunque no necesariamente justifique, la decisión legislativa a favor de la diferenciación del régimen aplicable al concurso ideal y el régimen aplicable al concurso real. Pues los argumentos a favor de la relativización de este principio de diferenciación, que pueden llegar incluso a favorecer la solución inversa, consistente en la adopción de un principio de unificación de uno y otro régimen, ${ }^{35}$ no dejan de ser atendibles.

La discusión al respecto muestra, en todo caso, que la adopción de un régimen punitivo más favorable para los casos de concurrencia de realizaciones

\footnotetext{
$32 \mathrm{El}$ derecho penal chileno prevé dos regímenes punitivos alternativos aplicables al concurso real: el del art. 74 del Código Penal, que consiste en un régimen de acumulación material de las penas asociadas a los hechos delictivos concurrentes; y el del art. 351 del Código Procesal Penal, que consiste en un régimen de formación de una pena única, o bien de exasperación de la pena mayor, siempre que los delitos concurrentes sean de la misma especie, esto es, siempre que afecten un mismo bien jurídico. Frente a ambos regímenes resulta más favorable, en todo caso, el régimen del concurso ideal (y medial), que consiste en la asperación o absorción agravada de la pena correspondiente al delito más grave.

${ }_{33} \mathrm{Al}$ respecto, y por todos en la doctrina alemana, Kindhäuser, Urs: LPK-StGB (nota 2), $₫ 52$, n.m. 4 ss.; en la doctrina española, por todos, Mir Puig, Santiago: Derecho Penal Parte General, 2005, 27/44 ss.

34 Kindhäuser, Urs: "Normverstoß und natürliche Handlungseinheit - BGH NJW 1984, 1568", JuS 1985, pp. 104 ss.

${ }^{35}$ Representativo en esta dirección, aunque matizando su planteamiento original, Freund, Georg: Strafrecht Allgemeiner Teil. Personale Straftatlehre, 2009, \$11/58 s.
} 
típicas en unidad de hecho - esto es, para los casos de concurso ideal- es una determinación que el legislador ciertamente puede hacer suya, pero que en ningún caso está obligado a hacer suya. Y puesto que todo concurso ideal es, en efecto, un concurso de delitos cuyos respectivos contenidos de ilicitud son recíprocamente independientes - pues de lo contrario habría que afirmar, más bien, un concurso aparente-, la cuestión se encuentra fuera del alcance del principio ne bis in dem. Lo cual quiere decir: la pregunta acerca de cuál ha de ser el régimen punitivo aplicable en casos de concurso ideal, en comparación con aquel aplicable en casos de concurso real, no depende del alcance de la prohibición de punición múltiple, desde ya porque se trata aquí de una determinación legislativa, en circunstancias de que la prohibición de punición múltiple no es vinculante para el legislador.

\section{d) Excurso: la unidad de hecho y el concurso ideal homogéneo}

$\mathrm{Al}$ igual que el concurso real, el concurso ideal puede asumir dos formas, según si los dos o más delitos que se encuentran en situación de unidad de hecho, en los términos recién expuestos, se corresponden con la realización de dos o más tipos delictivos diferentes, o bien con la realización de un mismo tipo delictivo dos o más veces. En el primer caso, el concurso ideal asume la forma de un concurso heterogéneo; en el segundo caso, de un concurso homogéneo.

Así, si a través de un solo disparo de un arma de fuego tiene lugar la realización de dos tipos delictivos diferentes, por ejemplo, la descripción del homicidio y la descripción del aborto, ya sabemos que hemos de reconocer la existencia de dos delitos o hechos delictivos diferentes, en relación de concurso ideal heterogéneo. Y asimismo, si a través de la detonación de una bomba se ve realizado tres veces el tipo delictivo del homicidio -porque a consecuencia de la explosión resultan muertas tres personas-, entonces hay que reconocer la existencia de tres delitos o hechos delictivos diferentes, en relación de concurso ideal homogéneo.

Esto último suele verse enfrentado a una importante objeción. Pues existen planteamientos que proponen excluir la posibilidad de un concurso ideal homogéneo que quedara sometido al régimen previsto por el art. 75 del Código Penal. Para ello usualmente se invocan dos argumentos. En primer lugar, se sostiene que el concepto de hecho, al que recurre el legislador en el inc. $1^{\circ}$ del art. 75 , abarcaría no sólo la acción sino también el resultado, en tanto se trate, en efecto, de delitos de resultado, por lo cual habría que reconocer tantos hechos como resultados delictivos vengan en consideración. ${ }^{36}$ Pero el problema es que este argumento, a diferencia de lo que pretenden quienes lo invocan, no puede simplemente llevar a concluir que estaría excluida la posibilidad de reconocer un concurso ideal homogéneo bajo el art. 75. Pues si el argumento se desarrolla

\footnotetext{
36 Véase Novoa, Eduardo: Curso de Derecho Penal Chileno, tomo II, 2005, p. 232; Garrido, Mario: Derecho Penal Parte General, tomo II, 2005, pp. 452 ss.
} 
REJ - Revista de Estudios de la Justicia - No 15 - Año 2011

consistentemente, lo mismo tendría que valer para cualquier caso de concurso ideal heterogéneo de dos o más delitos de resultado.

Así, en el caso del ejemplo ya mencionado, en el cual una persona causa la muerte de una mujer embarazada y también la muerte del feto que ella porta en su vientre a través del mismo disparo de un arma de fuego, es evidente que -bajo la hipótesis de que se satisfagan los respectivos presupuestos de imputaciónestaríamos en presencia de dos delitos de resultado, en la medida en que tanto la consumación del homicidio como la consumación del aborto dependen del acaecimiento de un resultado. ${ }^{37}$ Por ende, de aplicarse el criterio de que, para los efectos de la aplicación del art. 75, siempre habría tantos hechos como resultados, en el caso del ejemplo la conclusión tendría que ser la de negar la existencia de un concurso ideal (heterogéneo), para sostener, en cambio, la existencia de un concurso real. Pero ésta es una conclusión que en general los partidarios de la tesis aquí criticada no están dispuestos a validar. ${ }^{38}$ Luego, el primer argumento queda desvirtuado en atención a que, desde el punto de vista de la relación en que se encuentran los conceptos de hecho y de resultado, para los efectos de la aplicabilidad del art. 75 del Código Penal, no hay diferencia alguna entre los casos de concurso homogéneo y los casos de concurso heterogéneo. ${ }^{39}$

El segundo argumento, por su parte, apunta a que los términos en que se encuentra configurado el régimen de determinación de la pena previsto por el inc. $2^{\circ}$ del art. 75 lo volverían inaplicable a los casos de concurso ideal homogéneo. ${ }^{40}$ Ello, en la medida en que ese régimen consiste en identificar cuál es la pena correspondiente al delito más grave, que absorbe la pena de los demás delitos concurrentes, para así proceder a imponerla en su umbral máximo: "absorción agravada". Luego, se dice, dicho régimen no sería aplicable si los dos o más delitos concurrentes son de igual gravedad, que es precisamente lo que ocurriría en una situación de concurso ideal homogéneo.

Pero el argumento anterior desconoce que el mismo problema podría presentarse en una situación de concurso ideal heterogéneo. Pues es obvio que dos o más delitos de distinta especie stricto sensu -en el sentido de que cada uno de ellos consiste en la realización imputable de un tipo delictivo diferente- pueden

\footnotetext{
${ }^{37}$ La tesis de que el aborto es un delito cuya consumación depende de la producción del resultado consistente en la muerte del feto no ha estado exenta de controversia en la doctrina chilena tradicional. Fundamental para el desarrollo de dicha tesis, contraria a la definición del concepto jurídico-penal de aborto como mera interrupción del embarazo, Bascuñán Valdés, Antonio: "Nota a sentencia 'Contra Teresa Pastén”', Revista de Ciencias Penales, Tomo XXII, No 2, 1963, pp. 221 ss.

38 Véase Garrido, Mario: Derecho Penal (nota 36), tomo I, 2005, p. 435, quien afirma la existencia de un concurso ideal entre homicidio y aborto en el caso en que a través de la misma acción una persona causa la muerte de la mujer embarazada y la muerte del feto. Sugiriendo una tesis favorable al reconocimiento de un concurso real para tal caso, Novoa, Eduardo: Curso (nota 36), p. 232.

39 Así Etcheberry: Derecho Penal, tomo II, 1998. p. 121; Cury, Enrique: Derecho Penal Parte General, 2005, pp. 665 ss.

${ }^{40}$ Véase Garrido, Mario: Derecho Penal (nota 36), tomo II, p. 453.
} 
resultar de igual gravedad en atención a su respectiva penalidad. ${ }^{41}$ Piénsese, por ejemplo, en el caso de un sujeto que causa un aborto, ejerciendo violencia sobre la mujer embarazada, a consecuencia de lo cual ésta sufre lesiones corporales que le acarreen infertilidad. En la medida en que el autor haya actuado siquiera con dolo eventual respecto de la producción de dicho resultado de lesión corporal, consistente en la "impotencia" de la mujer, ${ }^{42}$ y suponiendo que se satisfagan las condiciones de imputación subjetiva del aborto en cuestión, cabría reconocer aquí un concurso ideal entre un delito de aborto con violencia del art. $342 \mathrm{~N}^{\circ} 1$ y un delito de lesiones gravísimas del art. $397 \mathrm{~N}^{\circ} 1{ }^{43}$ Ahora bien, ambos delitos son de igual gravedad, en la medida en que los respectivos marcos penales son idénticos: presidio mayor en su grado mínimo. Obviamente, esto no sería obstáculo para reconocer que lo que se da, en tal caso, es un concurso ideal (heterogéneo). Luego, nada distinto tendría que valer en caso de que el concurso ideal sea homogéneo: siendo los delitos concurrentes de igual gravedad, el tribunal ha de imponer la pena mayor correspondiente a cualquiera de ellos. ${ }^{44}$

\section{e) El concepto de hecho en sentido procesal}

El derecho procesal penal, finalmente, articula un ulterior concepto de hecho, el cual, según ya se anticipara, necesita ser definido en atención a las diferentes funciones que el proceso penal ha de satisfacer directamente en pos de contribuir a la realización funcional del derecho penal. En lo fundamental, el concepto de hecho en sentido procesal debe hacer posible identificar el respectivo objeto procesal, esto es $-\mathrm{y}$ haciendo abstracción de su elemento personal- el suceso fáctico que ha de ser objeto de juzgamiento jurídico-penal. ${ }^{45}$ El concepto de hecho en sentido procesal, en tal medida, desempeña una doble función, de máxima significación: por una parte, y bajo la vigencia del principio acusatorio, determina el objeto de la eventual sentencia definitiva, que debe coincidir, en los términos del principio de congruencia o correlación, con el objeto de la acusación formulada por el Ministerio Público, tal como lo dispone el art. 341 del Código Procesal Penal; por otra parte, determina el alcance del efecto (y la excepción) de cosa juzgada de la eventual sentencia definitiva, según lo establecido en los art. $1^{\circ}$

\footnotetext{
${ }^{41}$ Este concepto de delitos de la misma especie en sentido estricto no coincide, como es obvio, con el concepto de delitos de la misma especie al que recurre el art. 351 del Código Procesal Penal. Se trata más bien, del concepto de delitos de la misma especie que es propio de la regulación de la agravante por reincidencia específica del art. $12 \mathrm{~N}^{\circ} 16$.

42 A favor de la interpretación de "impotente" como abarcando la impotencia (generandi o coeundi) de una persona de sexo femenino, Politoff, Sergio; Grisolía, Francisco, y Bustos, Juan: Derecho Penal Chileno. Parte Especial, 1993, pp. 216 ss.

43 Para ello es fundamental reconocer que el concurso no podría ser calificado como aparente, en la medida en que el desvalor de las lesiones gravísimas ciertamente no queda comprendido por el desvalor del aborto violento. Con matices, a favor del concurso ideal en tal caso, Ibíd, p. 152.

${ }^{44}$ Así Etcheberry: Derecho Penal (nota 39), pp. 121 ss.

${ }^{45}$ Kindhäuser, Urs: Strafprozessrecht (nota 1), \25/1 ss., 4.
} 
REJ - Revista de Estudios de la Justicia - No 15 - Año 2011

inc. $2^{\circ}$ y 264 c) del Código Procesal Penal, así como, simétricamente, el alcance de la excepción de litis pendencia, prevista en el art. 264 b) del mismo Código. ${ }^{46}$

Tendría que resultar evidente, ahora bien, que el concepto procesal de hecho por definición no puede ser idéntico al concepto jurídico-penal de "hecho delictivo". Pues este último concepto, según ya se sostuviera, identifica la realización imputable de un determinado tipo delictivo, lo cual no puede tenerse por establecido sino cuando se pone término al procedimiento de cognición con el eventual pronunciamiento de una sentencia condenatoria. El objeto del proceso, en otras palabras, no puede ser identificado con el hecho delictivo que eventualmente resulte atribuible al imputado, ya que el proceso ha de encaminarse, de conformidad con su función de verdad, al establecimiento de si efectivamente tuvo lugar o no la perpetración de un hecho delictivo atribuible al imputado. Por lo demás, de identificarse el objeto procesal, propiamente, con el presunto hecho delictivo, sería conceptualmente imposible dar cuenta de que una sentencia absolutoria pronunciada en un primer enjuiciamiento, que estimara inexistente el hecho investigado, pudiera producir un impedimento procesal, en virtud de su efecto de cosa juzgada, para un nuevo juzgamiento relativo a ese mismo hecho. ${ }^{47}$

Antes bien, el concreto objeto procesal, identificado a través de la aplicación del concepto procesal de hecho, ha de resultar compatible con la posibilidad de que durante el proceso se produzcan modificaciones en la calificación jurídico-penal (provisional) de ese objeto, tal como lo contempla el Código Procesal, respecto de la relación entre acusación y sentencia, en el inc. $2^{\circ}$ del art. 341. Y esto sólo puede darse en la medida en que a través del concepto procesal de hecho se identifique un complejo de circunstancias susceptibles de ver modificada su específica calificación jurídico-penal. ${ }^{48}$

Por lo mismo, el concepto procesal de hecho tampoco necesita ser coextensivo con el concepto jurídico-penal de unidad de hecho, dado que éste no designa más que la forma de concurrencia de dos o más hechos delictivos que se corresponde con un concurso ideal. Y nuevamente, que esto sea el caso sólo puede ser establecido a través del desarrollo del proceso, en circunstancias que el concepto procesal de hecho tiene que posibilitar la identificación del objeto del proceso ya al momento de la formulación de la acusación, tal como lo prevé el art. 259 b) del Código Procesal Penal.

Lo anterior quiere decir que el concepto procesal de hecho tiene que ser definido de modo tal que la identificación de un hecho en tal sentido no dependa de la satisfacción de una (o más de una) determinada descripción de un

46 Ibíd, \25/5 ss.; en relación con el derecho procesal penal chileno, Del Río, Carlos: Los poderes de decisión del juez penal, 2009, pp. 131 ss., 147 ss. Véase también Horvitz, María Inés y López, Julián: Derecho Procesal Penal chileno, tomo II, 2004, pp. 37 ss.

47 Así ya Beling, Ernst: Derecho Procesal Penal, 2000, p. 85.

48 Ibíd, pp. 118 ss. En detalle respecto del derecho procesal penal chileno, Del Río, Carlos: Los poderes (nota 46), pp. 217 ss. 
comportamiento delictivo. Esto significa, entonces, que se trata de un concepto fuertemente extensional. En lo esencial, aquí compiten una concepción fáctica y una concepción normativo-fáctica de hecho en sentido procesal. ${ }^{49}$ Ninguna de estas concepciones disputa la autonomía del concepto procesal de hecho frente al concepto jurídico-penal de hecho (delictivo), en los términos ya analizados; ambas concepciones asumen, en otros términos, que los criterios de reconocimiento de un (mismo) hecho en sentido procesal no pueden ser los criterios de reconocimiento de un (mismo) hecho delictivo o bien de una unidad de hecho, en el sentido de un concurso ideal de delitos. La controversia, más bien, recae sobre cuáles han de ser esos criterios autónomos.

La concepción fáctica (o "naturalista"), que suele ser presentada como la concepción más tradicional, recurre a una "perspectiva natural" para identificar el "suceso vital histórico" en el marco del cual el imputado pudiera haber perpetrado un delito. ${ }^{50}$ Así, el parámetro decisivo parece reducirse a la existencia de una más o menos estrecha conexión espacio-temporal entre sucesos que, entonces, tendrían que ser juzgados como una unidad, el cual puede verse completado por un criterio subjetivo que exija algo cercano a una "unidad de voluntad". ${ }^{11}$ Por contrapartida, la concepción normativo-fáctica, si bien atribuye relevancia a los criterios relativos al tiempo y lugar de los acontecimientos, y al objeto de su incidencia, postula la necesidad de recurrir también a criterios "normativamente cargados", tales como la "dirección de ataque", la conmensurabilidad de los respectivos contenidos de ilicitud, la correspondencia de significación jurídico-penal de los diferentes tipos delictivos eventualmente realizados, entre otros. ${ }^{52}$

Una ventaja asociada a esta última concepción frente a la primera se halla referida a que ella, preservando la autonomía del concepto procesal de hecho, de todas maneras reconoce relevancia indirecta a criterios de valoración que son jurídico-penalmente relevantes. La clave se encuentra, a este respecto, en que el concepto procesal de hecho ha de posibilitar la identificación de un conjunto de sucesos que hayan de constituir un objeto de juzgamiento jurídico-penal unitario, en el sentido preciso de que ese conjunto de sucesos necesariamente haya de constituir el objeto de una única acusación. Y ésta es una pregunta que en ningún caso puede ser confundida con la pregunta acerca de si, en atención a razones de economía procesal, es procedente una acumulación de varias acusaciones, tal como lo prevé el art. 274 del Código Procesal Penal. ${ }^{53}$ Pues en este último caso, el objeto de cada una de las acusaciones acumuladas sigue representando un objeto procesal independiente, ${ }^{54}$ de modo tal que respecto de cada objeto procesal rigen,

\footnotetext{
${ }^{49}$ Kindhäuser, Urs: Strafprozessrecht (nota 1), \25/15 ss.; Del Río, Carlos: Los poderes (nota 46), pp. 149 ss.

${ }^{50}$ Kindhäuser, Urs: Strafprozessrecht (nota 1), \25/15.

${ }^{51}$ Del Río, Carlos: Los poderes (nota 46), pp. 149 ss., 152 ss.

52 Kindhäuser, Urs: Strafprozessrecht (nota 1), \ 25/16.

${ }^{53} \mathrm{Al}$ respecto Horvitz, María Inés y López, Julián: Derecho Procesal Penal chileno, tomo I, pp. 206 ss., tomo II pp. 54 ss.

${ }^{54}$ Así ya Beling, Ernst: Derecho Procesal Penal (nota 47), pp. 119 ss.
} 
por separado, las definiciones relativas al alcance del principio de congruencia y del efecto de cosa juzgada.

Puesto que el criterio último para la aplicación del concepto procesal de hecho apunta a la adecuación de un juzgamiento jurídico-penal unitario, la concepción normativo-fáctica está en mejor posición para reconocer la función (puramente) indiciaria que en este contexto asume la contraposición de las nociones de unidad de hecho y pluralidad de hechos en sentido jurídico-penal, que se corresponde con la distinción entre concurso ideal y concurso real, respectivamente. Así, mientras una posible relación de concurso ideal entre dos o más presuntos hechos delictivos -que han de encontrarse, en tal medida, en relación de unidad de hecho- puede considerarse como un indicio prácticamente irrefutable de la existencia de un solo hecho en sentido procesal,,$^{55}$ una posible relación de concurso real entre dos o más presuntos hechos delictivos -que han de encontrarse, en tal medida, en relación de pluralidad de hechos- sólo cuenta como un indicio débil de la existencia de distintos hechos en sentido procesal. ${ }^{56}$

La importancia de delimitar el concepto de hecho en sentido procesal, en lo que aquí interesa, se encuentra en que por esa vía es posible determinar el alcance del principio ne bis in idem en su dimensión de prohibición de juzgamiento múltiple, en la medida en que las excepciones de cosa juzgada y litis pendencia, a través de las cuales se hace operativa dicha prohibición, ven condicionada su aplicabilidad a que los dos o más juzgamientos (sucesivos o simultáneos, respectivamente) se encuentren efectivamente referidos a un mismo hecho en tal sentido. Como se mostrará más abajo, sin embargo, tal concepto de hecho en sentido procesal sólo encuentra reconocimiento, en el marco del derecho procesal penal chileno, en el contexto intrajurisdiccional, esto es, tratándose de la coexistencia de dos o más ejercicios de jurisdicción por parte de tribunales chilenos.

\section{Las prohibiciones de juzgamiento y punición múltiple en sus contextos}

\section{a) El contexto intraprocesal}

El primer escenario en que se plantea la pregunta por la medida de la vigencia del principio ne bis in idem bajo el derecho penal chileno se corresponde con lo que más arriba fuese denominado el "contexto intraprocesal", esto es, aquel contexto que se distingue por el hecho de que es al interior de un mismo proceso que se plantea la eventual aplicabilidad del principio en cuestión. Según ya se sostuviera,

${ }^{55}$ Kindhäuser, Urs: Strafprozessrecht (nota 1), \25/13. Al respecto Del Río, Carlos: Los poderes (nota 46), pp. 169 ss. Una conexión de medio (necesario) a fin entre dos hechos delictivos, que el legislador chileno toma en cuenta para someter el así llamado concurso medial al régimen punitivo del concurso ideal (art. $75 \mathrm{CP}$ ), también tendría que contar como indicio fuerte de la existencia de un solo hecho procesal.

${ }^{56}$ Kindhäuser, Urs: Strafprozessrecht (nota 1), \25/14. 
en este contexto el principio sólo puede resultar operativo en su dimensión de prohibición de punición múltiple, puesto que por definición carece de sentido plantear la aplicabilidad de una pluralidad de juzgamiento múltiple si se tiene a la vista una sola instancia u ocasión de juzgamiento. Igualmente importante es tener en cuenta que la prohibición de punición múltiple, en tanto estándar sustantivo de adjudicación, se especifica aquí como una prohibición cuyo alcance queda restringido por la referencia a un mismo hecho, en el sentido de un mismo delito o becho delictivo, de acuerdo con el análisis ya ofrecido de esta última noción. ${ }^{57}$

De acuerdo con lo ya planteado, son ante todo las categorías -elaboradas por el discurso de la dogmática jurídica- de la unidad de acción (u omisión) delictiva, por una parte, y del concurso aparente o impropio, por otra, las que vienen en consideración, como criterios de aplicación del derecho penal sustantivo, para hacer efectiva la prohibición de punición múltiple en el contexto que aquí interesa. Que una y otra categoría no cuenten con reconocimiento legal expreso de ningún modo obsta, ${ }^{58}$ empero, a su plena pertinencia y aplicabilidad bajo el derecho chileno vigente..$^{59}$ Pues el reconocimiento de una unidad de acción (u omisión) delictiva, que concierne la cuestión de la identificación de una única instancia de realización de un mismo tipo delictivo, resulta ser nada más que una operación inmanente a la identificación jurisdiccional del objeto de subsunción, mientras que el desplazamiento de una o más normas de sanción en atención a la aplicación preferente de otra, que lleva al reconocimiento de un concurso aparente, resulta ser un dato de la lógica de la aplicación (judicial) de la ley, sometida al desiderátum de evitar una sobrevaloración, contraria a la mejor representación interpretativamente atribuible al legislador, de las circunstancias que fundamentan la punibilidad o agravan la penalidad del comportamiento del imputado. ${ }^{60}$

Así, por un lado, junto a los tradicionales criterios de la "unidad típica de acción" y la "unidad natural de acción", la doctrina y la jurisprudencia chilena reconocen aquella forma de unidad ("jurídica") de acción conocida como "delito continuado", ${ }^{61}$ cuya función consiste, precisamente, en posibilitar la identificación

\footnotetext{
${ }^{57}$ Véase supra, 2.b)

58 Ello está lejos de constituir una anomalía. Si bien el Código Penal español de 1995 contiene regulación expresa relativa tanto al así llamado "delito continuado" (art. 74) -aunque sin configurarlo, propiamente, como una forma de unidad de acción delictiva- como a los criterios de reconocimiento de un concurso aparente (art. $8^{\circ}$ ), esto representa más bien la excepción. El Código Penal alemán, por ejemplo, tal como la generalidad de los códigos españoles anteriores al de 1995 no conocen regulación alguna en tal sentido.

${ }^{59}$ Véase, Piña, Juan Ignacio: Derecho Penal (nota 21), pp. 256 ss.

${ }^{60}$ Kindhäuser, Urs: LPK-StGB (nota 2), ante \$S 52-55, n.m. 20.

${ }^{61}$ Véanse por todos, y con matices, Novoa, Eduardo: Curso (nota 36), pp. 236 ss.; Garrido, Mario: Derecho Penal (nota 36), tomo II, pp. 440 ss. En la jurisprudencia más reciente, el reconocimiento de la construcción del delito continuado es bastante generalizado, lo cual no obsta, por cierto, a que sus contornos permanezcan aún altamente indeterminados. Para una muestra representativa véanse, por ejemplo, las sentencias: Corte Suprema, de 26 de marzo de 1996, rol No 311-96; Corte
} 
REJ - Revista de Estudios de la Justicia - No 15 - Año 2011

de un conjunto de instancias de realización de un mismo tipo delictivo como un solo hecho delictivo, bloqueando así el reconocimiento de un eventual concurso real (homogéneo). Por otro lado, también se encuentra doctrinal y jurisprudencialmente asentado el recurso a los criterios que tradicionalmente hacen posible la afirmación del carácter aparente o impropio de un concurso de delitos -paradigmáticamente: especialidad, subsidiariedad (tácita), consunción-, en pos de evitar la doble consideración de una misma circunstancia o una misma propiedad de un hecho con relevancia jurídico-penal. ${ }^{62}$

Lo anterior muestra que el principio ne bis in idem se hace operativo, en este contexto, a través de categorías históricamente elaboradas por la dogmática jurídica, sin que resulte necesaria -ni eventualmente deseable- su consagración legal expresa. ${ }^{63}$ Esto no obsta, sin embargo, a que la prohibición de la punición múltiple, específicamente en su concreción como prohibición de doble valoración, sí se encuentre legalmente consagrada en algunos ámbitos específicos.

El primer ejemplo lo proveen todas aquellas cláusulas, insertadas junto a la tipificación de determinadas formas delictivas, que expresan una solución de subsidiariedad expresa a favor del carácter aparente de un eventual concurso de delitos. Así, cuando el encabezado del art. 391 del Código Penal, que tipifica las distintas variantes de homicidio stricto sensu, incorpora la cláusula "no esté comprendido en el artículo anterior" (que tipifica el parricidio), se hace manifiesta la preocupación legislativa frente a una eventual contravención de la prohibición de doble valoración, que se produciría si al autor de un parricidio también se lo condenase como autor de un homicidio por el mismo hecho (en sentido extensional).

El otro ejemplo que cabe mencionar aquí es la regla del art. 63 del mismo código, relativa a la eventual inherencia (formal o material) de determinadas circunstancias agravantes respecto de la tipificación del respectivo delito. Si una circunstancia, legalmente reconocida como agravante, es constitutiva ya del hecho delictivo de cuya imputación se trata, o se encuentra contenida explícita o implícitamente por la tipificación del mismo, entonces -por exigencia del principio ne bis in idem- no puede ser tomada en consideración en la determinación de la pena correspondiente.

\section{b) El contexto interprocesal}

En el marco del derecho chileno vigente, el escenario correspondiente al "contexto interprocesal", ya definido, varía considerablemente respecto del anterior. Y ello en dos sentidos. Esto, porque en este contexto, por una parte, el

de Apelaciones de Temuco, 24 de abril de 2008, rol No 345-08; Corte de Apelaciones de Arica, 24 de mayo de 2010, rol No $80-10$.

62 Véanse por todos, y con matices, Novoa, Eduardo: Curso (nota 36), pp. 247 ss., 251 ss.; Garrido, Mario: Derecho Penal (nota 36), tomo II, pp. 457 ss.

${ }^{63}$ En este sentido ya Novoa, Eduardo: Curso (nota 36), p. 251. 
principio ne bis in idem se encuentra expresamente consagrado, aunque en su dimensión exclusiva de prohibición de juzgamiento múltiple; y por otra, porque el alcance de esta prohibición de juzgamiento múltiple queda definido por la referencia a un mismo hecho, en el sentido de un mismo hecho procesal, de acuerdo con el análisis ya ofrecido de esta última noción. ${ }^{64}$ Las dos consideraciones se dejan fundamentar en atención directa al inc. $2^{\circ}$ del art. $1^{\circ}$ del Código Procesal Penal, que consagra el principio de "única persecución" en los siguientes términos:

La persona condenada, absuelta o sobreseída definitivamente por sentencia ejecutoriada, no podrá ser sometida a un nuevo procedimiento penal por el mismo hecho.

Que aquí se trata, exclusivamente, de la prohibición de juzgamiento múltiple, resulta manifiesto ante el tenor literal de la disposición, que restringe el objeto de la prohibición al sometimiento a "un nuevo procedimiento penal". Esto no quiere decir, ciertamente, que en el contexto interprocesal pueda asumirse la irrelevancia per se de la dimensión de la prohibición de punición múltiple. De lo que se trata, más bien, es que la inhibición de la punición múltiple, bajo esta consagración del principio ne bis in idem como estándar de clausura procesal, deviene un efecto reflejo de la prohibición de juzgamiento múltiple, siempre que el resultado de un eventual primer juzgamiento haya sido la imposición de una pena a través de la correspondiente sentencia condenatoria.

Hay que apuntar, de paso, que en la disposición citada el principio ne bis in idem se encuentra exclusivamente formulado como una prohibición de juzgamiento sucesivo múltiple, lo cual se obtiene como consecuencia interpretativa de que el presupuesto de aplicación de la regla está constituido por el pronunciamiento de una sentencia ejecutoriada que haya dado lugar, con efecto de cosa juzgada material, a una condena, una absolución o un sobreseimiento definitivo de la misma persona en relación con el mismo hecho. Esto no quiere decir, ciertamente, que el derecho procesal penal chileno no reconozca una prohibición de juzgamiento simultáneo múltiple; ésta se expresa, antes bien, en la consagración de la litis pendencia como excepción de previo y especial pronunciamiento, en paralelo a la excepción de cosa juzgada, tal como lo prevé el art. 264 del Código Procesal Penal.

Como ya se adelantara, lo fundamental es reparar, en segundo término, en el alcance que la disposición legal confiere a la prohibición de juzgamiento múltiple. Su extensión es mayor que la que determina el alcance de la prohibición de punición múltiple en el contexto intraprocesal. En efecto, para que se haga operativa la prohibición de juzgamiento múltiple del art. $1^{\circ}$ del Código Procesal Penal basta con que el objeto de juzgamiento constituya "el mismo hecho" que fuera objeto de juzgamiento anterior. Y por "el mismo hecho" cabe entender aquí

\footnotetext{
${ }^{64} \mathrm{Al}$ respecto supra, 2.e).
} 
lo que más arriba fuese definido como un solo hecho en sentido procesal. La razón para esto se conecta con un doble aspecto del diseño del proceso penal. Por una parte, se trata de una condición imprescindible para la existencia de continuidad en el desarrollo del proceso en caso de producirse una modificación en su calificación jurídica (provisional). Pues lo que garantiza esa continuidad es precisamente la identidad del objeto procesal en el tiempo. Luego, si el objeto del proceso está constituido por un mismo hecho en sentido procesal, la vigencia del principio de congruencia, complementado por el principio de recalificación, exige que la identidad de ese hecho no se vea alterada por su eventual recalificación.

Pero esto también se vincula, por otra parte, con una condición de legitimación de la persecución penal, que concierne a dos de las funciones cuya realización compete al diseño del proceso penal. ${ }^{65}$ De un lado, existe un requerimiento de justicia procedimental, relativo a la asimetría de la posición de los intervinientes en el proceso, que se traduce en que al Ministerio Público se reconozca, prima facie al menos, una única oportunidad para hacer efectiva la pretensión punitiva estatal a través del ejercicio de la acción penal pública. De lo contrario, el órgano persecutor podría someter reiteradamente a una misma persona a la contingencia de la persecución penal, sin verse constreñido por la exigencia de satisfacer estándares de rigor y exhaustividad en la identificación de las circunstancias fácticas relevantes bajo el derecho eventualmente aplicable por el tribunal competente. En tal medida, a la garantía de la persecución única también cabe atribuir un efecto colateral de incentivo a la prudencia en la persecución penal. Y de otro lado, según ya se indicara, la función de certeza jurídica que también ha de realizar el diseño procesal se traduce en la exigencia de que el ejercicio de jurisdicción respecto del objeto del proceso se convierte en una respuesta jurídicamente definitiva a la incertidumbre asociada a la eventual perpetración de un hecho delictivo.

Por ello, en la medida en que la prohibición (interprocesal) de juzgamiento múltiple opera por referencia al juzgamiento del mismo hecho en sentido procesal, y no del mismo delito o hecho delictivo en sentido jurídico-penal, su alcance resulta más amplio que el de la prohibición (intraprocesal) de punición múltiple. Sigue siendo una cuestión abierta, en el marco del derecho procesal chileno, cuáles han de ser los criterios específicos para el reconocimiento de una identidad de hecho en sentido procesal. Parece suficientemente claro, sin embargo, que en la medida en que dos o más hechos delictivos concurrentes se encuentren vinculados por una relación de unidad de hecho en sentido jurídicopenal, al modo de un concurso ideal, en todo caso habrá que asumir que tales hechos delictivos configuran un solo hecho en sentido procesal.

\footnotetext{
${ }^{65} \mathrm{Al}$ respecto supra, 2.a).
} 


\section{c) El contexto interjurisdiccional}

En cambio, no puede decirse lo mismo de la manera en que el principio ne bis in idem se hace operativo en el escenario correspondiente a lo que más arriba fuese definido como el "contexto interjurisdiccional". Pues aquí, según ya se anticipara, aparece la variable relativa a la medida en que la jurisdicción de un Estado soberano pueda quedar negativamente condicionada por el reconocimiento del ejercicio de jurisdicción de otro Estado soberano. La medida precisa del reconocimiento del "efecto en Chile de las sentencias penales de tribunales extranjeros" queda delimitada, como también se adelantara, por las reglas expresadas en el art. 13 del Código Procesal Penal. El contraste entre el tenor de esta disposición y el tenor del inc. $2^{\circ}$ del art. $1^{\circ}$ del mismo código pone de manifiesto el considerable menor alcance que exhibe el principio ne bis in idem cuando pretende reclamar aplicación en un contexto interjurisdiccional, quedando sujetado al principio del reconocimiento mutuo del ejercicio de jurisdicción de los respectivos Estados. Puede ser útil, por lo mismo, considerar por de pronto lo dispuesto en el inc. $1^{\circ}$ del art. 13 :

Tendrán valor en Chile las sentencias penales extranjeras. En consecuencia, nadie podrá ser juzgado ni sancionado por un delito por el cual hubiere sido ya condenado o absuelto por una sentencia firme de acuerdo a la ley y al procedimiento de un país extranjero, a menos que el juzgamiento en dicho país hubiere obedecido al propósito de sustraer al individuo de su responsabilidad penal por delitos de competencia de los tribunales nacionales o, cuando el imputado lo solicitare expresamente, si el proceso respectivo no hubiere sido instruido de conformidad con las garantías de un debido proceso o lo hubiere sido en términos que revelaren falta de intención de juzgarle seriamente.

A diferencia de lo establecido en el art. $1^{\circ}$ del mismo código, el principio ne bis in idem aparece consagrado aquí tanto en su dimensión de prohibición de juzgamiento múltiple ("juzgado") como en su dimensión de punición múltiple ("sancionado"). La segunda parte del inciso citado, ahora bien, hace inequívocamente reconocibles los límites que se imponen al reconocimiento del ejercicio de jurisdicción penal por parte de un tribunal extranjero, en relación con una y otra dimensión del principio. La referencia a la posibilidad de que ese juzgamiento haya "obedecido al propósito de sustraer al individuo de su responsabilidad por delitos de competencia de los tribunales nacionales", así como a la posibilidad de que el proceso respectivo no haya "sido instruido de conformidad con las garantías de un debido proceso" o haya sido instruido de un modo que revele una "falta de intención de juzgarle seriamente", cuenta como demostración concluyente de un principio de confianza restringida en cuanto a la legitimidad y la efectividad del ejercicio de jurisdicción foránea. 
Esta consideración es decisiva, a su vez, para entender por qué la disposición expresamente formula tanto una prohibición de juzgamiento múltiple como una prohibición de punición múltiple, a diferencia de lo previsto por el art. $1^{\circ}$; esto es, para entender por qué la disposición no se limita a establecer una prohibición de juzgamiento múltiple, cuyo efecto reflejo pudiera consistir, entonces, en la inhibición de una eventual punición múltiple. La respuesta a esta pregunta es la siguiente. En los casos en que, por satisfacerse alguno de los presupuestos mencionados en la segunda parte del inc. $1^{\circ}$ del art. $13-y$ siempre que, tratándose de la hipótesis de vulneración de las garantías del debido proceso o falta de intención de juzgamiento serio, exista solicitud expresa por parte del imputado- decaiga la prohibición de un posterior juzgamiento por parte de un tribunal chileno, de todas formas subsiste la posibilidad de que a consecuencia del primer juzgamiento -no obstante la irregularidad de éste- la persona haya ya sufrido la imposición de una sanción por el mismo hecho delictivo que es objeto del nuevo juzgamiento. En tal situación, rige lo dispuesto en el inc. $2^{\circ}$ del mismo art. 13:

En tales casos, la pena que el sujeto hubiere cumplido en el país extranjero se le imputará a la que debiere cumplir en Chile, si también resultare condenado.

Es decir: siempre que el proceso ante el tribunal extranjero haya dado lugar a la imposición de una pena, y siempre que ésta haya sido efectivamente ejecutada o cumplida en el extranjero, ello tendrá que computarse en el cumplimiento de la pena eventualmente impuesta por el tribunal chileno a consecuencia del segundo juzgamiento.

Todo lo anterior presupone, sin embargo, que uno y otro juzgamiento hayan estado referidos a un mismo "delito", tal como lo exige el inc. $1^{\circ}$ del art. 13, lo cual, según ya se adelantara, limita decisivamente el alcance del principio ne bis in idem en el contexto interjurisdiccional. Aquí, tanto la prohibición de juzgamiento múltiple como la prohibición de punición múltiple resultan únicamente aplicables en tanto haya identidad entre el hecho delictivo por el cual la persona fuera condenada o absuelta ante un tribunal extranjero y el hecho delictivo al cual se halle referido el posterior juzgamiento por parte de un tribunal chileno. Así, el art. 13 prescinde del concepto (fuertemente) extensional que funciona como designación de un (mismo) hecho en sentido procesal en los términos del art. $1^{\circ}$, adoptando, en cambio, un concepto intensional de hecho delictivo. Y ello se traduce en que, frente a una sentencia condenatoria o absolutoria pronunciada por un tribunal extranjero, ${ }^{66}$ el principio ne bis in idem sólo opere, inhibiendo un juzgamiento o la imposición de una sanción penal por un tribunal chileno, en la medida en que el hecho que cuenta como objeto del

66 Puesto que el art. 13 presupone la existencia de una decisión de condena o absolución establecida por sentencia firme, cabe concluir que el principio ne bis in idem no opera, en este contexto, frente a sentencias extranjeras que dieran lugar, meramente, a un sobreseimiento. 
juzgamiento o como antecedente de la sanción consista en la misma realización de la misma forma (o tipo) de comportamiento delictivo.

Lo anterior no representa más que la formulación explícita de la doble cuestión de identidad que siempre se encuentra involucrada en el reconocimiento de un mismo delito o hecho delictivo, a saber: la cuestión relativa a la identidad de la descripción de la forma de comportamiento delictivo, de un lado, y la cuestión relativa a la identidad de la acción (u omisión) que realiza la descripción en cuestión, de otro. ${ }^{67}$ Puesto que la segunda cuestión de identidad siempre se encuentra supeditada, por definición, a la primera -en el sentido de que la determinación de si una descripción ha sido realizada una o más veces depende de cuál sea esa descripción-, cabe asumir aquí que es la cuestión relativa a la identidad de la descripción de la forma de comportamiento delictivo la que da lugar a las mayores dificultades. En este marco, es suficiente con establecer cuáles son las posibilidades a disposición del intérprete.

Por una parte, es obvio que el concepto de un mismo delito presupone una relación de congruencia entre una y otra descripción que necesariamente ha de superar la exigencia mínima identificada con el principio de doble incriminación, tal como éste suele consagrarse en la regulación de los procedimientos de extradición. ${ }^{68}$ Pero por otra, no es obvio sin más que esa relación de congruencia entre una y otra descripción haya de ser entendida como una relación de identidad en sentido lógico-formal, ${ }^{69}$ esto es, como la exigencia de que la extensión de una y otra sea exactamente la misma, de modo tal que cada hecho subsumible bajo una de ellas sea al mismo tiempo subsumible bajo la otra, y viceversa. ${ }^{70}$ Antes bien, en este contexto puede resultar sensato orientar la pregunta acerca de la identidad de dos o más descripciones de formas de comportamiento delictivo hacia los criterios relativos a la independencia del respectivo fundamento de la ilicitud que son invocados, en el contexto intraprocesal, para afirmar el carácter aparente o impropio de un concurso de delitos. ${ }^{71}$ $\mathrm{Y}$ estos criterios se dejan sintetizar a través de la siguiente fórmula: dos descripciones de comportamiento delictivo son (total o parcialmente) idénticas cuando comparten una o más de aquellas propiedades que cuentan como

\footnotetext{
${ }^{67}$ Véase supra, 2.b)

${ }^{68} \mathrm{El}$ art. 449 b) del Código Procesal Penal exige, como requisito de la extradición pasiva, que "de los antecedentes del procedimiento pudiere presumirse que en Chile se deduciría acusación en contra del imputado por los hechos que se le atribuyen".

69 Coincidentemente acerca de la interpretación de la exigencia de "un mismo delito" en el contexto de la cláusula de la doble exposición de la Constitución federal de los EE.UU., Thomas, George: "A Blameworthy Act Approach to the Double Jeopardy Same Offense Problem", 1995, pp. 1033 ss.

${ }^{70}$ Para esta definición de la relación lógico-formal de identidad entre dos o más descripciones de formas de comportamiento delictivo, véase Klug, Ulrich: "Zum Begriff der Gesetzeskonkurrenz", 1956, p. 404

71 Véanse por todos, en la doctrina alemana, Jakobs, Günther: Strafrecht Allgemeiner Teil, 1991, 31/12; Kindhäuser, Urs: $L P K-S t G B$ (nota 2), ante $\$ \int 52-55$, n.m. 20; en la doctrina española, Mir Puig, Derecho Penal (nota 33), 27/64.
} 
fundamento del carácter específicamente delictivo del objeto de la respectiva descripción. ${ }^{72}$

Lo importante, en lo que aquí interesa, es reparar en una consecuencia fundamental que se sigue de esto para la determinación del alcance del principio ne bis in idem en el contexto interjurisdiccional. Pues de conformidad con lo anterior, en la medida en que un hecho (en sentido extensional) haya sido objeto de juzgamiento o haya dado lugar a la imposición de una sanción por parte de un tribunal extranjero bajo una descripción que no comparta el mismo contenido de ilicitud con la descripción bajo la cual ese hecho pudiera ser objeto de juzgamiento o dar lugar a la imposición de una sanción por parte de un tribunal chileno, no vendrá en consideración entonces, un mismo delito para los efectos del art. 13 del Código Procesal Penal. Éste sería desde luego el caso, por ejemplo, si la específica lesividad de la realización de una y otra descripción fuese diversa en atención a la diversidad de la naturaleza o de los titulares de los bienes jurídicos concretamente afectados.

72 Precisamente en esta dirección se orientan los criterios normativos propuestos por Moore, Michael: Act and Crime (nota 27), pp. 337 ss.; y Thomas, George: "A Blameworthy Act..." (nota 69), pp. 1041 ss. 


\section{BIBLIOGRAFÍA}

* BASCUÑán VALDÉS, Antonio: "Nota a sentencia 'Contra Teresa Pastén”", Revista de Ciencias Penales, Tomo XXII, No 2, $3^{a}$ época (1963).

* BELING, Ernst: Derecho Procesal Penal, DIN editora, Buenos Aires, 2000.

* BINDING, Karl: Handbuch des Strafrechts, Scientia Verlag, Aachen, 1991 (orig. 1885).

* COlOMER HerNÁNDEZ, Ignacio: "Conflictos de jurisdicción, non bis in idem y litispendencia internacional en la Unión Europea”, en Arroyo Zapatero y Nieto Martín (coords.), El principio de ne bis in idem en el Derecho penal europeo e internacional, Ediciones de la Universidad Castilla-La Mancha, Cuenca, 2007.

* CuRY, Enrique: Derecho Penal Parte General, $8^{\text {a }}$ ed., Ed. Universidad Católica de Chile, Santiago, 2005.

* DEL RÍO, Carlos: Los poderes de decisión del juezpenal, Ed. Jurídica de Chile, Santiago, 2009.

* ETCHEBERry, Alfredo: Derecho Penal, tomo II, $3^{a}$ ed., Ed. Jurídica de Chile, 1998.

* FREUND, Georg: Strafrecht Allgemeiner Teil. Personale Straftatlehre, $2^{\mathrm{a}}$ ed., Springer, Berlín/Heidelberg, 2009.

* GARRIDO, Mario: Derecho Penal Parte General, $4^{a}$ ed., Ed. Jurídica de Chile, tomo II, Santiago, 2005.

* HECKER, Bernd: Europäisches Strafrecht, $3^{\mathrm{a}}$ ed., Springer, Heidelberg, 2010.

* HORVITZ, María Inés y LÓPEZ, Julián: Derecho Procesal Penal chileno, Ed. Jurídica de Chile, dos tomos, Santiago, 2002 y 2004.

* JAKOBS, Günther: Strafrecht Allgemeiner Teil. Grundlagen und Zurechnungslebre, $2^{\mathrm{a}}$ ed., Walter de Gruyter, Berlín, 1991.

* KINDHÄUSER, Urs: Lehr- und Praxiskommentar zum Strafgesetzbuch [LPK-StGB], 4ª ed., Nomos, Baden-Baden, 2010.

"Normverstoß und natürliche Handlungseinheit - BGH NJW 1984, 1568”, JuS 1985.

Strafprozessrecht, Nomos, Baden-Baden, $1^{a}$ ed., 2006.

* KLUG, Ulrich: “Zum Begriff der Gesetzeskonkurrenz”, ZStW 68 (1956).

* MAÑALICH, Juan Pablo: "El concurso de delitos: bases para su reconstrucción en el derecho penal de Puerto Rico", Revista Jurídica de la Universidad de Puerto Rico 74 (2005). "La pena como retribución", Estudios Públicos 108 (2007).

Terror, pena y amnistía. El derecho penal ante el terrorismo de Estado, Flandes Indiano, Santiago, 2010.

* MIR Puig, Santiago: Derecho Penal Parte General, $7^{\mathrm{a}}$ ed., BdF, Montevideo/Buenos Aires, 2005.

* MOORE, Michael: Act and Crime. The Philosophy of Action and its Implications for Criminal Law, Oxford University Press, Oxford, 1993.

* NIETO, Alejandro: Derecho Administrativo Sancionador, Tecnos, Madrid, 1993.

* NOVOA, Eduardo: Curso de Derecho Penal Chileno, $3^{\mathrm{a}}$ ed., Ed. Jurídica de Chile, 2 tomos, Santiago, 2005.

* PIÑA, Juan Ignacio: Derecho Penal. Fundamentos de la responsabilidad, Abeledo Perrot/Legal Publishing, Santiago, 2010.

* POlitoff, Sergio, GrisolíA, Francisco y BUSTOS, Juan: Derecho Penal Chileno. Parte Especial, $2^{a}$ ed., Ed. Jurídica de Chile, Santiago, 1993.

* PUPPE, Ingeborg: Strafrecht Allgemeiner Teil, Nomos, tomo II, Baden-Baden, 2005.

* SARMIENTO, Daniel: "El principio ne bis in idem en la jurisprudencia del TJCE", en Arroyo Zapatero y Nieto Martín (coords.), El principio de ne bis in idem en el Derecho penal europeo e internacional, Ediciones de la Universidad Castilla-La Mancha, Cuenca, 2007.

* SATZGER, Helmut y KAYSER, Julia: "Ne bis in idem en el derecho penal internacional: muchas preguntas a segunda vista”, en Arroyo Zapatero y Nieto Martín (coords.), El principio de ne bis in idem en el Derecho penal europeo e internacional, Ediciones de la Universidad Castilla-La Mancha, Cuenca, 2007. 
REJ - Revista de Estudios de la Justicia - No 15 - Año 2011

* SILVA SÁNCHEZ, Jesús-María: La expansión del derecho penal. Aspectos de la política criminal en las sociedades postindustriales, $2^{\mathrm{a}}$ ed., Civitas, Madrid, 2001.

* SUAY RINCÓN, José: Sanciones Administrativas, Real Colegio de España, Madrid, 1989.

* THOMAS III, George: "A Blameworthy Act Approach to the Double Jeopardy Same Offense Problem”, California Law Rev. 83 (1995). 